\title{
Effect of COVID-19 Infodemic on Media Trust and Perceived Stress
}

\author{
Sanni Shamsudeen Ademola'), Neema Rajabu'2), \\ Chinecherem Umezuruike3), Lasisi Kamoru Alamu4)
}

\begin{abstract}
1) Department of Computer Science, Faculty of Science and Engineering, University of Eswatini 2)Faculty of Computer Science and Information Technology, Kampala International University 3)Department of IT, School of Mathematics and Computing, Kampala International University 4)Department of Telecommunication Engineering, Kampala International University
\end{abstract}

\section{ABSTRACT}

Background: Health infodemic undermines public health response, results in poor observance of public health measures and costs lives. Health campaigns will not produce intended results without controlling misinformation. This study aimed to analyzed the correlation between infodemic, COVID-19 stress and media trust.

Subjects and Method: This was a cross sectional study conducted using online structured questionnaire, from December 2020 to January 2021. A total of 470 participants among African twitter community were randomly selected for this study. The dependent variables were COVID-19 stress and media trust. The independent variable was while Infodemic serve. The data was analysed using Pearson's product moment correlation coefficient test.

Results: COVID-19 stress $(\mathrm{r}=0.369 ; \mathrm{p}<0.001)$ and media trust $(\mathrm{r}=0.301 ; \mathrm{p}<0.001)$ were correlated with infodemic and it was statistically significant.

Conclusion: infodemic is correlated with COVID-19 stress and media trust.

Keywords: infodemic, health communication, media trust, stress, COVID-19

\section{Correspondence:}

Sanni Shamsudeen Ademola. Department of Computer Science, Faculty of Science and Engineering, University of Eswatini, Private Bag 4, Matsapha, manzana, Kingdom of Eswatini. Email: sanniadeo1@gmail.com. Mobile: +26876241155/79241155.

\section{Cite this as:}

Ademola SS, Rajabu N, Umezuruike C, Alamu LK (2021). Effect of COVID-19 Infodemic on Media Trust and Perceived Stress. J Health Promot Behav. 06(02): 144-153. https://doi.org/10.26911/thejhpb.2021.06.02.07.

() (9) Journal of Health Promotion and Behavioris licensed under a Creative Commons Attribution-NonCommercial-ShareAlike 4.o International License.

\section{BACKGROUND}

The COVID-19 disease outbreak devastated the whole world leading to a global pandemic, lockdown of cities, flight restrictions, border closures, restrictions in movement, curfews, cancellation in sports, entertainment activities and stay at home orders. This resulted in stagnation in educational, business and economic activities. Altogether, people relied on family and friends, local authorities, traditional news media, the World Wide Web and Social Networking Sites (SNSs) for information on the pandemic. There was a surge in infodemic; an explosion of misinformation during the pandemic, some individuals, groups and businesses use online platforms to deliberately spread false or misleading information. It descended to a low point where people started to treat every COVID-19 related information with suspicion. 
Communication of appropriate health messages is basic for good health behaviour and effective management of disease outbreak demands for high level expertise in coordination, communication and collaboration (CDC, 2019; Maunder et al., 2003; Perrett et al., 2003). While coordination and collaboration were left to the prerogative of government and public health experts, communication about the COVID-19 outbreak was free for all as conspiracy theorists, rumour mongers and propagandists were granted a field day. This makes it difficult for people to receive reliable guidance on how to handle the pandemic.

Most countries around the world had relied on WHO guidelines and directives on COVID-19, but COVID-19 related misinformation intrudes on the overabundance of news, mixing facts, rumours and fake news (Naffi et al., 2020). Negative contents were created, shared and forwarded on social networking sites (SNSs), leading to confusion, anxiety, fear, stress, anger and frustration. Mocking videos of the aftermath effects of vaccination were trending on SNSs, implying that people who were administered COVID-19 vaccines display abnormal behaviour or physical disability. As with SARS in 2003, Ebola in 2014, Zika in 2016, there were COVID-19 denials and vaccine sceptics who based their conviction on information received from media sources. Misinformation was spreading faster than the virus (Cinelli et al., 2020) it elevates public anxieties and worries (Lin CY, 2020), having damaging effects on public response and people's behaviour in taking proper precautions, leading to wrongdecision making, loss of lives and slow recovery.

Previous studies on the effect of disease outbreak on social and mental wellbeing are revealing. Maunder et al. (2003) observed feelings of anger, guilt, fear, bore- dom and loneliness amongst patients of SARS in 2003. Patients fear for the welfare of friends and family; they worry about stigmatization, resentment and loss of income as a result of being quarantined (Maunder et al., 2003). Some other studies (Cheung, 2015; Lin CY, 2020), have observed increase in racism, discrimination and stigmatization during disease outbreak, which generally results from lack of adequate information and misinformation. Similar occurrence was reported during the COVID-19 pandemic, Chinese and East Asians living in Europe and America experienced all sorts of discrimination, from assaults to denial of service, while African immigrants, students and business men were assaulted and evicted from their homes in Guangdong province, which has China's largest African community (HRW, 2020; Islam et al., 2020).

Social Networking Sites (SNSs) are generally relied upon by a growing number of the populace for information (Lin CY, 2020; Neema and Sanni, 2020), since it tolerates a disintermediated production, access and retrieval of information (Sanni and Neema, 2020; Scala et al., 2020). A recent study by Datta et al., (2020), revealed that $68.2 \%$ of the participants in their survey felt they were misinformed on social media about the pandemic. Trending topics, opinions and perspectives on SNSs shape public perceptions, evoking social debates, influence policy making, political communication, and decision making. This behavior, attitude and decision making as a result of messages received through social media could be explained through the lenses of health communication, social science and human behaviour theories. While SNSs has become a very powerful tool to galvanize public perception, it has also become the most powerful platform for misleading information. Misinformation or fake news 
spread faster on SNSs than factual information. With that in mind, SNSs could also be a catalyst for clarification campaigns, proper awareness and sensitization if strategically deployed and become less of a tool for spreading misinformation and fake news. Awareness of the new media strategy could help the public separate facts from fictions and make correct decisions when it comes to sourcing news from new media platforms.

After studying COVID-19 social media infodemic, Cinelli et al., (2020) revealed that spread of information is controlled by the nature of interaction that takes place in a particular social media platform, suggesting that the dangers of infodemic are platform specific. The manner of information and the chosen medium can strongly influence people's behaviour and alter the effecttiveness of the countermeasures deployed by governments and their task-force (Cinelli et al., 2020). The effect of infodemic on mental health is catastrophic and long lasting and this could have a damaging effect on media trust or media platforms.

With this background, the COVID-19 pandemic experience should force us to reevaluate the role of both traditional and new media in health communication and behavioural change. It becomes necessary to develop mechanisms to reduce and stem the tide of misinformation. This study investigates the effect of COVID-19 infodemic on media trust and perceived stress through the lenses of health communication theories. Findings from this study could help address the problem of infodemic, improve health communication strategies and models.

\section{SUBJECTS AND METHOD}

\section{Study Design}

This was a cross sectional study conducted using online structured questionnaire, from December 2020 to January 2021.

\section{Population and Sample}

The population studied was all Twitter Microblogging users in Africa. Sampling was carried out using random sampling technique to select twitter microblogging users in Africa. A total of 470 subjects were selected for this study..

\section{Study Variables}

The dependent variables are COVID-19 Stress and Media Trust. The independent variable was Infodemic.

\section{Operational Definition of Variables} Perceived Stress (COVID-19stress) refers to the level at which an individual perceived stress a result of COVID-19 pandemic.

Infodemic refers to the level at which individuals believe, rely and act upon misinformation received on COVID-19 pandemic. The scale of measurement in this variable is Never to Very Often.

New Media Knowledge is the extent to which an individual is confident in his/her ability to separate facts from fake news, misinformation and clickbait with scale No Confidence to Highly Confident.

Social Media Trust refers to the level of trust an individual has of news and information received from social media sources (Scale: Strongly Disagree to Strongly Agree)

Traditional Media Trust is a level of trust an individual has of news and information received from traditional media sources.

Media Trust refers to the level of trust an individual has of news and information received from all media sources.

Behavior is a person's action in responding

\section{Instruments}

The data is in the form of primary and secondary data. Primary data were obtained 
using Google Form filled out by research subjects.

\section{Data Analysis}

Univariate analysis was carried out to see frequency distribution and characteristics of the research subjects, while bivariate analysis was performed using Pearson's product moment correlation coefficient test.

Table 1. Characteristics of study subjects (Categorical data)

\begin{tabular}{llcc}
\hline \multicolumn{1}{c}{ Characteristics } & \multicolumn{1}{c}{ Categories } & Frequency (n) & Percentage (\%) \\
\hline Gender & Female & 157 & 33.4 \\
Age & Male & 313 & 66.6 \\
& $17-24$ & 66 & 14.0 \\
& $25-34$ & 159 & 33.8 \\
& $35-44$ & 172 & 36.6 \\
& $45-54$ & 54 & 11.5 \\
Field/Occupation & $55-64$ & 14 & 3.0 \\
& 65 or older & 5 & 1.1 \\
& Academics & 158 & 33.6 \\
& Entrepreneurs & 77 & 16.4 \\
& Students & 71 & 15.1 \\
& Engineering, Computing and IT & 64 & 13.6 \\
& Public servants & 48 & 10.2 \\
& Private firms & 33 & 7.1 \\
& Medical Practitioners & 19 & 4.0 \\
& Master's Degree & 159 & 33.8 \\
& Bachelor Degree & 119 & 25.3 \\
& PhD & 96 & 20.4 \\
& Undergraduate & 55 & 11.7 \\
& Post Graduate Degree & 38 & 8.1 \\
& Others & 2 & 0.4 \\
& Fellowship & 1 & 0.2 \\
\hline
\end{tabular}

Table 2. showed that the characteristic of study subjects (continuous data), the mean of infodemic $(\mathrm{Mean}=1.71 ; \mathrm{SD}=1.00 ; 95 \%$ $\mathrm{CI}=1.62$ to 1.81 ), New media knowledge (Mean $=2.97 ; \mathrm{SD}=0.81 ; 95 \% \mathrm{CI}=2.89$ to 3.05), COVID-19 Stress (Mean= 2.26; $\mathrm{SD}=$

\section{RESULTS}

\section{Sample Characteristics}

Table 1 showed the sample characteristics of the study. The majority of the subjects were male (66.6\%), most of the subjects were 35-44 (36.6) years old. The majority of them had a master degree education level (33.8\%) and worked as academics (33.6\%).

0.83; $95 \% \mathrm{CI}=2.20$ to 2.36$)$, social media trust $(\mathrm{Mean}=2.23 ; \mathrm{SD}=0.84 ; 95 \% \mathrm{CI}=2.14$ to 2.30), trad media trust (Mean $=3.37$; $\mathrm{SD}=0.92 ; 95 \% \mathrm{CI}=1.30$ to 1.32$)$ and also media trust $(\mathrm{Mean}=1.80 ; \mathrm{SD}=0.69 ; 95 \%$ $\mathrm{CI}=1.73$ to 1.86 ). 
Ademola et al./ Effect of COVID-19 Infodemic on Media Trust and Perceived Stress

Table 2. Characteristics of study subjects (continous data)

\begin{tabular}{lccccc}
\hline \multicolumn{1}{c}{ Variable } & n & Mean & SD & 95\% CI \\
\cline { 5 - 6 } & & & & Lower Limit & Upper Limit \\
\hline Infodemic & 459 & 1.71 & 1.00 & 1.62 & 1.81 \\
New Media Knowledge & 463 & 2.97 & 0.81 & 2.89 & 3.05 \\
COVID-19 Stress & 464 & 2.26 & 0.83 & 2.20 & 2.36 \\
Soc Media Trust & 451 & 2.23 & 0.84 & 2.14 & 2.30 \\
Trad Media Trust & 458 & 3.37 & 0.92 & 1.30 & 1.32 \\
Media Trust & 445 & 1.80 & 0.69 & 1.73 & 1.86 \\
\hline
\end{tabular}

\section{Bivariate Analysis}

Table 3. Correlations between infodemic and COVID-19 stress

\begin{tabular}{lccc}
\hline \multirow{2}{*}{ Variabel } & \multicolumn{2}{c}{ COVID-19 Stress } \\
\cline { 2 - 3 } & $\mathbf{r}$ & $\mathbf{p}$ \\
\hline Infodemic & 0.37 & $<0.001$ \\
\hline
\end{tabular}

Table 3 showed the correlation between infodemic and COVID-19 stress $(\mathrm{r}=0.37$;

$\mathrm{p}<0.001)$ and its was statistically Table 4. Correlations between infodemic and media trust

\begin{tabular}{ccc}
\hline Independent Variabel & \multicolumn{2}{c}{ Media Trust } \\
\cline { 2 - 3 } & $\mathbf{r}$ & $\mathbf{p}$ \\
\hline Infodemic & 0.30 & $<0.001$ \\
\hline
\end{tabular}

Table 4 showed the correlation between infodemic and media trust $(\mathrm{r}=0.301 ; \mathrm{p}$ $<0.001)$ and its was statistically significant.

\section{DISCUSSION}

Infodemic refers to deliberate attempts to disseminate malicious information online and offline for material, political or financial gain, in order to undermine public health response or advance alternative realities, conspiracy theories of groups or individuals. Findings from this study suggest that infodemic is a very serious problem in fighting the COVID-19 pandemic; people are stressed by the pandemic, especially with the misinformation and fake news making rounds which make them sometimes nervous, confused and unsettled.

Majority of the subjects perceived themselves to have a good understanding of the new online media environment; most can recognise phishing and click bait that trigger users to open fake news links and visit fake news pages. No one is immune to receiving or coming across fake news online or offline, we have less control over news flash on our TV set, pop up ads on our gadgets, what is shared in our WhatsApp group, what appears on our Twitter threads or posted on Facebook pages. However, the difference comes in the ability to separate fake news from fact-based news and the ability to update our media settings to control what we see, view or read.

Fake news is hard to fight because it is financially motivated and there has been an increase in COVID-19 related scams including treatment, medication, testing and vaccines scams during the pandemic which might have added to public anxiety, anger and frustration. In the wake of the COVID19 infodemic, social networking sites are redesigning their platforms to tackle the infodemic by making it uneconomical and difficult for people to post misleading and fake news. Fact-checking efforts have signi- 
ficantly expanded and have been touted as among the most promising solutions to fake news (Ceron et al., 2020). Our findings also suggest that there is a low level of trust for information shared through social media, such as Facebook, Twitter, Instagram, Youtube and WhatsApp. However, there is a very high level of trust for information presented in traditional media, such as Television, Radio, Newspapers and Books. This finding is consistent with that of Datta et al., (2020) who found that lots of people believe they were misinformed on social media about the COVID-19 pandemic. The implication of this finding is for leading voices in the fight against the pandemic to intensify health messages in traditional media as people have a higher level of trust for news and information disseminated through these mediums. They should make efforts to stay ahead of fake news merchants on social media through dedicated messages that focus on correcting misinformation and calling out or blacklisting individuals or groups notorious for fake news.

There must be a clear communication of official media outlets of government health ministries and agencies to the public. This will assist the public to understand the scale of the problem, and be able to verify every information with what is provided by healthcare educators through their various official media outlets. There must be no tolerance for the spread of information that contradicts proper observance of public health measures in the society. A very significant correlation was observed between infodemic and COVID-19 related stress, suggesting that infodemic is dangerous to health and could affect healthy living. The world is facing a catastrophic moral failure with the rate at which COVID-19 misinformation is spreading and we are now seeing the same with COVID-19 vaccines, creating a world of vaccine sceptics. There are calls for social media regulations and laws, which have already been promulgated in many countries with penalties for spreading fake news. There must be a way to make people responsible and accountable for what they post or share on social media.

Furthermore, the study observed a significant correlation between infodemic and lack of media trust, suggesting that misinformation reduces the trust people have in the media. This is a serious challenge for health communication, as lack of trust could severely impede health campaign efforts in the future. Results also revealed differences between age groups in relation to COVID-19 stress and found that individuals within the age group $17-24$ (undergraduates) experience higher levels of stress compared to other age groups. Teenagers and undergraduates are more vulnerable and fragile during a pandemic, therefore special attention should be given to their mental health and wellbeing, special programs should be designed to assist them, especially in poor communities and villages with lack of basic amenities, ICT, medical and health infrastructure. Many students find it hard to convince parents and guardians that classes have moved online, while at home. These parents find it hard to understand or afford their kids hours of screen time per day, as they consider it a form of indolence and insolence. Students complained about parents denying them online-time and alternatively prefer they work in the farm, carry out domestic chores or help the family business when online lectures are supposed to be going on. These results in stress and frustration on the affected students.

The study recommends that the government should take sensitization campaigns through physical community outreach, radio, local TV broadcast and SMS to 
create awareness about online learning and its benefits during pandemic lockdown. Our findings are almost uniformly consistent with recent studies on the effect of online learning on students during COVID-19 pandemic (Adnan and Anwar, 2020; Bestiantono et al., 2020; Coman et al., 2020; Irawan at al., 2020).

Stress experienced by students was as a result of school closure, restriction in movement and stay at home orders. It was very difficult for schools, parents, teachers and students to adjust to online education, which could have a damaging impact on mental health and overall wellbeing. It has also been revealed that school closure increases dropouts and teenage pregnancies especially in poor communities. Meanwhile, tech companies need to take their message of cyber security consciousness to communities through physical visitations, posters, billboards, radio, TV and SMS messages. This will go a long way in reducing cybercrimes during pandemic lockdown. The result of this study would spur more research activities on the topic of infodemic and its impact on different areas of individual health and societal life.

The findings will have implications on health communication, information medium development, design and interactions. Majority of the participants in this study are academics and students, therefore, future researchers could focus on a different social system and see if findings could be different, as this would add to our stock of knowledge on this topic. Researchers, educators, practitioners and developers should continue to develop new approaches and tools for health communication campaigns to stem the tide of infodemic. Government must be proactive in formulating laws to control the spread of deliberately harmful messages both online and offline.

\section{AUTHOR CONTRIBUTION}

Sanni Shamsudeen Ademola conceptualized and designed the research idea, he coordinated the study and was involved in co-writing the entire paper. Neema Rajabu was actively involved in designing the research framework, identifying the theoretical lenses on which the study was structured. Chinecherem Umezuruike participated in the critical review of literature, data collection, data processing, data analysis and interpretation of results. Lasisi Kamoru Alamu likewise collaborated in reviewing relevant literature for the study, identifying gaps in research, data collection, data processing, data analysis and interpretation of results.

\section{FUNDING AND SPONSORSHIP}

This study is self-funded.

\section{CONFLICT OF INTEREST}

There is no conflict of interest in this study.

\section{ACKNOWLEDGMENT}

The researchers are grateful to individuals who took their time to participate in this study and also acknowledge Google and Twitter for allowing us to use their platforms for free to conduct the research.

\section{REFERENCES}

Adnan M, Anwar K (2020). Online learning amid the COVID-19 pandemic: Students perspectives. JPSP. 2(1): 45-51. DOI: 10.33902/JPSP. 2020261309.

Ajzen I (1991). The theory of planned behavior. Organizational Behavior and $\mathrm{Hu}-$ man Decision Processes. 50(2): 179211. DOI: 10.1002/hbe2.195.

Bestiantono DS, Agustina PZR, Cheng TH (2020). How students perspectives about online learning amid the covid19 pandemic?. Studies in Learning And Teaching.; 1(3): 133-139. DOI: 
Ademola et al./ Effect of COVID-19 Infodemic on Media Trust and Perceived Stress

10.46627/silet.v1i3.46.

CDC (2017). Guidance for the evaluation and public health management of suspected outbreaks of meningococcal disease. Atlanta, GA: US Department of Health and Human Services. 12 Availaible at: https://www.cdc.gov/

Cheung EYL (2015). An outbreak of fear, rumours and stigma. Intervention.; 13(1): 70-76. DOI: 10.1097/wtf.oooooooooooooo79.

Chuan CL (2006). Sample size estimation using krejcie and morgan and cohen statistical power analysis: a comparison. Jurnal Penyelidikan IPBL.; 7: 79-86. Availaible at: http://www.ipbl.edu.my/portal/penyelidikan/jurn alpapers/jurnal2006/chuao6.pdf

Chyung SYY, Barkin JR, Shamsy JA (2018). Evidence-based survey design: the use of negatively worded items in surveys. Performance Improvement. 57(3):1625. DOI: 10.1002/pfi.21749.

Cinelli M, Cresci S, Galeazzi A, Quattrociocchi W, Tesconi M (2020). The limited reach of fake news on Twitter during 2019 European elections. PLoS ONE. 15(6): 1-13. DOI: 10.1371/journal.pone.0234689.

Coman C, Țîru LG, Meseșan-Schmitz L, Stanciu C, Bularca MC (2020). Online teaching and learning in higher education during the coronavirus pandemic: students perspective. Sustainability (Switzerland). 12(24): 1-22. DOI: $10.3390 /$ su122410367.

Couper MP (2000). Web surveys: a review of issues and approaches. The Public Opinion Quarterly. 64(4): 464-94. https://www.jstor.org/stable/307873 9

Edgar T, Volkman JE (2012). Using communication theory for health promotion: practical guidance on message design and strategy. Health Promot
Pract.; 13(5): 587-90. DOI: 10.1177/1524839912450879

Fishbein M (1979). A theory of reasoned action: some applications and implications. Nebraska Symposium on Motivation.; 26: 65-116. Available at : https://psycnet.apa.org/record/198221121-001

Fricker RD (2016). Sampling Methods for Online Survey. Available at : https://citeseerx.ist.psu.edu/viewdoc/downlo ad?doi=10.1.1.720.4424\&rep=rep1\&ty pe $=$ pdf

Howard PL, Bowman B (2017). I am the man: meanings of masculinity in perceptions of voluntary medical adult male circumcision for HIV prevention in South Africa. Psychology of Men \& Masculinity, Educational Publishing Foundation.; 18(1): 70-77. DOI: $10.1037 /$ menooooo39.

HRW (2020). China: COVID-19 discrimination against africans: forced quarantines, evictions, refused services in Guangzhou. New York, USA. Available at: https://www.hrw.org/news/2020/05/05/china-covid-19-discrimination-against-africans.

Islam MS, Sarkar T, Khan SH, Kamal AHM, Hasan SMM, Kabir AYeasmin D, et al. (2020). COVID-19-Related infodemic and its impact on public health: A global social media analysis. American Journal of Tropical Medicine and Hygiene.; 103(4): 1621-1629. DOI: 10.4269/ajtmh.20-0812.

Kim AE, Hansen HM, Murphy J, Richards AK, Duke J, Allen JA (2013). Methodological considerations in analyzing twitter data. Journal of the National Cancer Institute Monographs. London: Oxford University Press.; (47): 140-146. DOI: 10.1093/jncimonographs/lgto26.

Krejcie RV, Morgan DW (1970). Deter- 
mining sample size for research activities. Educational and Psychological Measurement.; 30(3): 607-610. Available at: https://journals.sagepub.com/doi/abs/10.1177/001316447 o03000308?journalCode=epma.

Lenght RV (2001). Some practical guidelines for effective sample size determination. The American Statistician.; 55(3): 187-193. (1964). DOI: 10.1198/oo0313001317098149

Lin CY (2020). Social reaction toward the 2019 novel coronavirus ( Covid - 19 ). Soc Health Behav. 3(1-2): DOI: 10.4103/SHB.SHB.

Maunder R, Hunter J, Vincent L, Bennet J, Peladeau N, Leszcz M, Sadavoy J, et al. (2003). The immediate psychological and occupational impact of the 2003 SARS outbreak in a teaching hospital. Cmaj. 168(10): 1245-1251. Availaible at https://psycnet.apa.org/record/2003-08317-001

Mayer KH (2011). Introduction: linkage, engagement, and retention in hiv care: essential for optimal individualand community-level outcomes in the era of highly active antiretroviral therapy. Clinical Infectious Diseases. BioMed Central.; 52(2): S205-S207. DOI: 10.1093/cid/ciq043.

Naffi N, Davidson AL, Jawhar H (2020). Five ways to help stop infodemic, The Conversation. Available at: https://theconversation.com/5-ways-to-helpstop-the-infodemic-the-increasingmisinformation-about-coronavirus137561.

Neema R, Sanni SA (2020). Interactive health information chatbot for noncommunicable diseases in swahili language. Journal of Applied Sciences, Information, and Computing (JASIC). 1(2). Availaible at :https://jasic.kiu.ac.ug/articleview.php?i=16\&t =interactive-healthinformationchatbot-for-non-communicablediseases-in-swahili-language

Perrett K, al-Wali W, Read C, Redgrave PTU (2003). Outbreak of meningococcal disease in Rotherham illustrates the value of coordination, communication, and collaboration in management. Commun Dis Public Health. 3(3): 168-71. Availaible at: https://europepmc.org/article/med/1 1014027

Rogers EM (2003). Diffusion of innovations. 5th edn. New York: Free Press. Availaible at: https://books.google.com/books?hl=en\&lr $=\&$ id $=$ viii 4 QsB7 jIC\&oi $=$ fnd\&pg $=$ PR15\&ots $=$ DMVstKX s4Q\&sig $=7$ PP_EKX63mLsItqtRzkkbu $\mathrm{nJzBk} \# \mathrm{v}=$ onepage\&q\&f$=$ false

Ruben BD (2016). Communication theory and health communication practice: the more things change, the more they stay the same. Health Communication. 31(1): 1-11. DOI: 10.1080/10410236.2014.923086

Sanni SA, Neema R (2020). Challenges to health information dissemination in tanzania and the opportunities provided by chatbot in swahili language. Journal of Applied Sciences, Information, and Computing (JASIC).; 1(2). Availaible at : https://jasic.kiu.ac.ug/articleview.pp?i=12\&t $=$ chall engestohealthinformationdisseminati onintanzaniaandtheopportunitiesprovidedbychatbotinswahili-language

Sanni SA, Neemah R, Fagbolu O (2018). Interactive chatbot to support interns during internship program. in THE 8th East African Higher Education Quality Assurance Forum (EAQAN) May 7 - 10, 2018. Kigali, Rwanda. Kigali: East Africa Quality Assuarance Commission (EAQAN): 1-11.

Scala A, Flori A, Spelta A, Brugnoli E, 
Cinelli M, Quattrociocchi W, Pammolli F (2020). Time space and social interactions : exit mechanisms for the COVID-19 epidemics. Scientific Reports. Nature Publishing Group UK.; 10: 1-12. DOI: 10.1038/s41598-02070631-9.

Stephenson MT, Southwell BG (2006). Sensation seeking, the activation model, and mass media health campaigns: current findings and future directions for cancer communication. Journal of Communication.; 56(1): 38-56. DOI:10.1111/j.1460-2466.2006.00282.x

Taherdoost H (2017). Determining sample size; How to calculate survey sample size. International Journal of Economics and Management Systems.; 2(2): 237-239. DOI:10.1177/001316447003000308
Witte GM, Martell D (2001). Effective health risk messages: a step-by-step guide. Thousand Oaks, CA: SAGE Publications. Availaible at: https://www.proquest.com/openview/948fef 955bee744efa6d7cbebodcfdfa/1?pqori gsite $=$ gscholar $\& \mathrm{cbl}=860$

Zoller HM (2005). Health activism: communication theory and action for social change, communication theory. International Communication Association.; pp. 341-364. DOI: https://doi.org/10.1111/j.14682885.2005.tbo 0339. $\mathrm{x}$

Zuckerman M (1994). Behavioral expressions and biosocial bases of sensation seeking. Cambridge. England.: Cambridge University Press. Availaible at: https://psycnet.apa.org/record/199497961-000 